\title{
Functional display of fungal cellulases from Trichoderma reesei on phage M13
}

\author{
Anzhou Ma $\cdot$ Qing Hu $\cdot$ Zhihui Bai $\cdot$ Yinbo Qu · \\ Weifeng Liu · Guoqiang Zhuang
}

Received: 6 June 2007/ Accepted: 16 February 2008/Published online: 27 February 2008

(C) Springer Science+Business Media B.V. 2008

\begin{abstract}
To test whether the phage display technology could be applied in cellulase engineering, phagemids harboring the genes encoding the mature forms of cellobiohydrolase I (CBH I) and endoglucanase I (EG I) from filamentous fungus Trichoderma reesei were constructed, respectively. CBH I and EG I fused to the phage coat protein encoded by the $g 3$ gene were expressed and displayed on phage M13. The phage-bound cellulases retained their activities as determined by hydrolysis of the corresponding substrates, Also, their binding abilities to insoluble cellulose substrate were confirmed by an ELISA method. Overall, these results demonstrate that cellulases can be displayed on phage surface while maintaining their biological function, thus providing an alternative for directed evolution and high-throughput screening for improved cellulases.
\end{abstract}

Keywords Cellobiohydrolase I · Endoglucanase I · Phage-cellulase $\cdot$ Phage display $\cdot$ Trichoderma reesei

$\begin{array}{ll}\begin{array}{ll}\text { Abbreviations } \\ \text { ABTS, 2 }\end{array} & \begin{array}{l}\text { 2'-Azino-bis-3-ethylbenzthiazoline-6- } \\ \text { sulfonic acid }\end{array} \\ \text { CBD } & \begin{array}{l}\text { Cellulose-binding domain } \\ \text { CBH I }\end{array} \\ & \text { Cellobiohydrolase I }\end{array}$

A. Ma $\cdot$ Y. Qu $\cdot$ W. Liu $\cdot$ G. Zhuang

State Key Laboratory of Microbial Technology, Shandong

University, Jinan 250100, China

W. Liu

e-mail: weifliu@sdu.edu.cn

Q. Hu $\cdot$ Z. Bai $\cdot$ G. Zhuang $(\bowtie)$

Research Center for Eco-Environmental Sciences, Chinese

Academy of Sciences, Beijing 100085, China

e-mail: gqzhuang@rcees.ac.cn

$\begin{array}{ll}\text { CD } & \text { Catalytic domain } \\ \text { EG I } & \text { Endoglucanase I } \\ \text { epPCR } & \text { Error-prone PCR } \\ \text { IPTG } & \text { Isopropyl- } \beta \text {-D-thiogalactopyranoside } \\ \text { P III } & \text { Gene-3-protein of filamentous phage } \\ \text { PBS(T) } & \text { Phosphate-buffered saline (with 0.05\% } \\ & \text { Tween 20) } \\ \text { PEG } & \text { Polyethylene glycol } \\ \text { MUC } & \text { 4-Methylumbelliferyl- } \beta \text {-D-cellobiose } \\ 2 \times \text { YT- } & 2 \times \text { YT Medium supplied with } 100 \mu g \\ \text { A(K)(G) } & \text { ampicllin/ml (70 } \mu \mathrm{g} \text { kanamycin } / \mathrm{ml}) \\ & (2 \% \text { glucose) }\end{array}$

\section{Introduction}

Cellulose, a linear homopolymer of $\beta-1,4$ linked anhydro glucose units, is the most abundant and renewable biopolymer in the earth (Jarvis 2003; Mansfield et al. 1999). Converting cellulosic biomass to biofuels such as ethanol is considered to be an important alternative to the exhaustion of fossil energies (Demain et al. 2005; Kamm and Kamm 2004; Ragauskas et al. 2006). Multi-component cellulase systems from filamentous fungi such as Trichoderma are usually the main architects of cellulose degradation in industrial application (Kirk et al. 2002; Lynd et al. 2002). However, characteristics of cellulases including the relatively low hydrolysis efficiency and the rapidly decreased hydrolytic rate during the hydrolysis process usually result in decreased sugar yields, high enzyme input, and long reaction time, which has been always considered to be the major impediment to the commercial conversion of cellulose. Although the cost of cellulases for the biomass-tobiorefineries has been reduced by combined strategies, cellulases are still relatively costly which limit their 
applicability as biocatalysts in processing (Moreira 2005; Zhang et al. 2006). So it is necessary to improve the enzymatic properties such as activity and stability till it is practical.

Directed evolution has been a powerful tool in enzyme engineering where no detailed structural information of a given protein is required (Cherry and Fidantsef 2003; Otten and Quax 2005; Wong et al. 2006). In combination with various combinatorial mutagenesis methods, directed evolution has been successful in engineering quite a few industrially important enzymes (Chirumamilla et al. 2001; McCarthy et al. 2004). Among others, a well-designed selection or screening strategy typically constitutes the critical step in successfully exploiting the generated molecular diversity. By displaying libraries of mutated proteins on microbial cell surface has thus proved to be a very effective method in this regard. Proteins displayed on cell surface usually adopt the proper conformation and the gene encoding the desired mutant can be simultaneously obtained. Recently, bacterial cell surface display of an carboxymethyl cellulae library for selective screening of improved cellulase variants has been reported (Kim et al. 2000). However, cell-based display has its inherent limitation which prevents it being used under harsh conditions (Wittrup 2001).

As an alternative, phage display has made a tremendous impact on the discovery of peptides binding to a variety of receptors and high-affinity antibodies, and it has been widely used to select and engineer peptides and proteins (Fernandez-Gacio et al. 2003; Kehoe and Kay 2005; Smith 1985). Recently, this technology has also been used in the directed evolution of enzymes taking advantage of the larger libraries it could accommodate and the direct linkage between the phenotype and genotype (Atwell and Wells 1999; Jarvis 2003). Enzymes displayed on phage have also been successfully screened for desired variants with improved biofunction (Ponsard et al. 2001; Verhaert et al. 2002). In this study, we tested the feasibility of applying the phage display technology to screen an enzyme library of desired cellulase variants. Importantly, we showed that either endoglucanase or cellobiohydrolase from Trichoderma reesei can be functionally displayed on phage M13, which offers a potentially useful platform for future directed evolution and high-throughput screening of improved enzymes.

\section{Materials and methods}

Bacterial strains, plasmids and media

Escherichia coli TG1 (Lyophilized; K12 $\Delta$ (lac-pro), sup $\mathrm{E}$, thi, hsd $\mathrm{D} 5 / \mathrm{F}^{\prime}$, traD36, pro $\mathrm{AB}$, lacIq, lac $\mathrm{Z} \Delta$-M15) was used as a suppressor strain for displaying the target protein fused to P III. E. coli HB2151 (Lyophilized; K12 $\Delta$ (lacpro), ara, nal $^{\mathrm{r}}$, thi $/ \mathrm{F}^{\prime}$, pro $\mathrm{AB}$, lacIq, lac $\mathrm{Z} \Delta$-M15) was used for expression of soluble recombinant protein. pCANTAB $5 \mathrm{E}$ (Amersham Bioscience) was used in phage display experiments. Media used for cultivation were described in the manual of expressing module/recombinant phage antibody system (Amersham Bioscience). E. coli was grown in Luria-Bertani (LB) medium containing $5 \mathrm{~g}$ yeast extract/l; $10 \mathrm{~g}$ tryptone/l; and $5 \mathrm{~g} \mathrm{NaCl} / \mathrm{l}$. For selection, ampicllin was added to a final concentration of $100 \mu \mathrm{g} / \mathrm{ml}$. Cell growth was determined by the absorbance value at $600 \mathrm{~nm}$ with a spectrometer.

Phagemid construction

The cellulase genes were amplified from pAJ401-EG I and pUCmT-CBH I harboring $e g I$ and $c b h I$, respectively. PCR was performed by use of vent DNA polymerase (New England Biolabs) with primers with additional $S f i$ I and $N o t$ I restriction sites shown in Fig. 1. For amplification of $c b h$ $I$, PCR conditions were 1 cycle of $95^{\circ} \mathrm{C}$ for $3 \mathrm{~min}$ followed by 30 cycles of $95^{\circ} \mathrm{C}$ for $2 \mathrm{~min}, 60.5^{\circ} \mathrm{C}$ for $1 \mathrm{~min}$ and $72^{\circ} \mathrm{C}$ for $2 \mathrm{~min}$. Thermol cycling parameters of amplification of eg $I$ were the same as those of $c b h I$ except for the annealing temperature at $65^{\circ} \mathrm{C}$. For both CBH I and EG I, the amplified cellulase genes only encoded their mature forms without the signal sequence and the stop condon. The PCR products were purified and concentrated using cycle-pure kit (Omega Bio-tech, USA). The target cellulase genes were digested with $S f i$ I and Not I (New England Biolabs) before being inserted into the pCANTAB 5E digested with the same enzymes with quick ligation kit (New England Biolabs). The two recombinant phagemids were termed pEG I and pCBH I, respectively.

\section{Transformation and phage preparation}

E. coli TG1 competent cells were transformed by electroporation by use of a MicroPulser (Bio-Rad laboratories) (Sheng et al. 1995). The ligation mixture of the appropriate phagemid was desalted and concentrated with cycle-pure kit before being used for electroporation. Transformants were plated on SOBAG (5 g yeast extract, $20 \mathrm{~g}$ tryptone, and $0.5 \mathrm{~g} \mathrm{NaCl} / 1$ and $0.01 \mathrm{M} \mathrm{MgCl}_{2}$ ) agar plates containing $100 \mu \mathrm{g}$ ampicllin/ml and $20 \mathrm{mM}$ glucose, and were incubated at $30^{\circ} \mathrm{C}$ overnight. The separated colonies (TG1/ pCBH I, TG1/pEG I) on the selective plates were picked to $2 \times$ YT-AG $(10 \mathrm{~g}$ yeast extract, $17 \mathrm{~g}$ tryptone, and $5 \mathrm{~g}$ $\mathrm{NaCl} / 1$ plus $100 \mu \mathrm{g}$ ampicllin/ml and $2 \%$ (w/v) glucose) medium and cultured at $37^{\circ} \mathrm{C}$ to an $\mathrm{OD}_{600}$ of 0.8 . M13KO7 $\left(4 \times 10^{10}\right.$ p.f.u. $)$ was then added in the culture with constantly shaking at $37^{\circ} \mathrm{C}$ for an hour. Superinfected 
Fig. 1 Schematic diagram of phagemid construction (a) Primers used for PCR reaction (b). Abbreviations of $\mathrm{CD}$ and CBD denote catalytic domain and cellulose binding domain, respectively. Forward primer (CBH I For) and reverse primer (CBH I Rev) were used in ampilification of $c b h I$. Forward primer (EG I For) and reverse primer (EG Rev) were used in ampilification of $e g I$

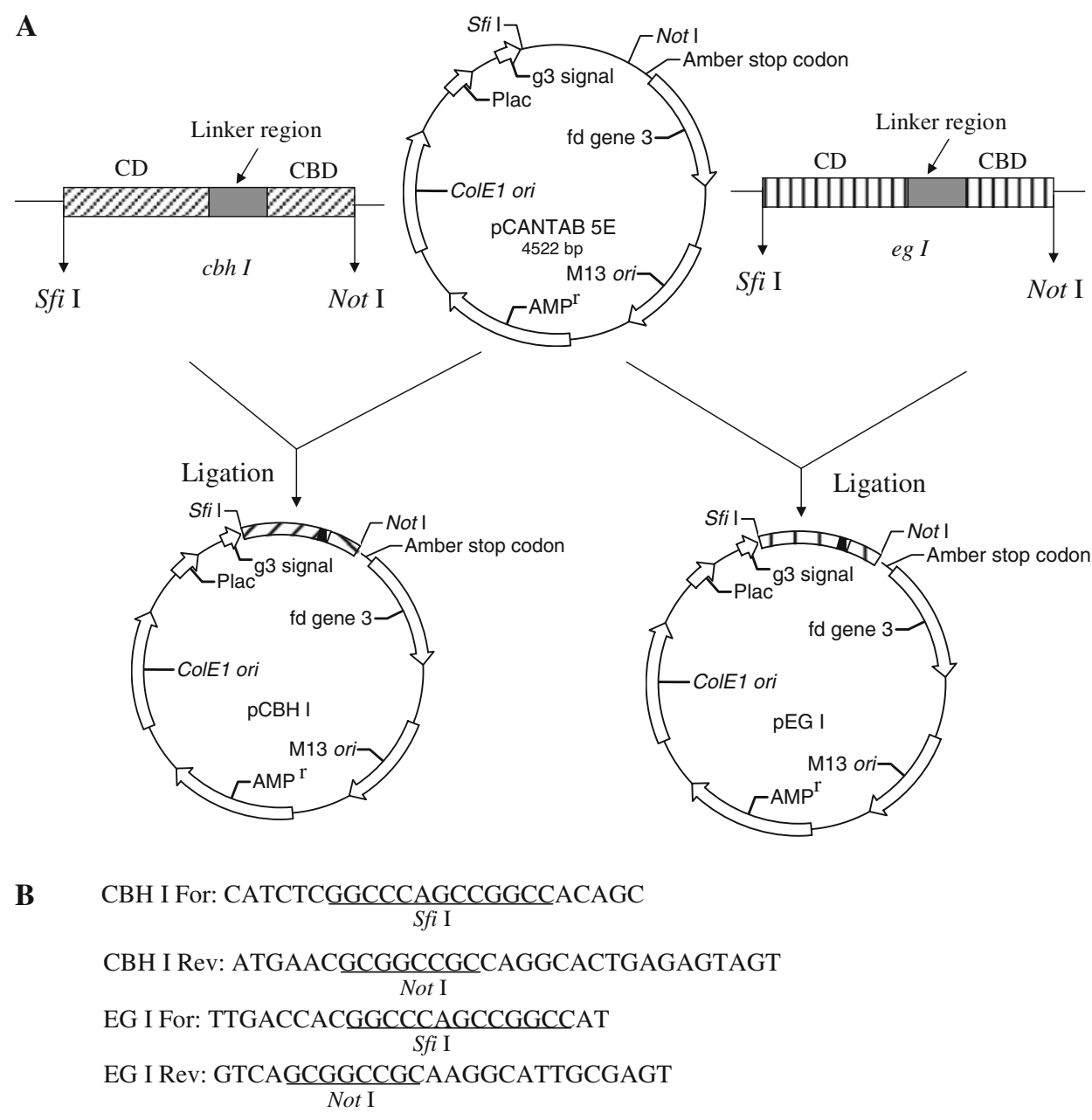

cells were harvested by centrifugation, and the pellet was re-suspended in $2 \times$ YT-AK with $100 \mu \mathrm{g}$ ampicllin and $70 \mu \mathrm{g}$ kanamycin $/ \mathrm{ml}$, and continued shaking at $37^{\circ} \mathrm{C}$ overnight. Routinely, the released phage particles were precipitated from the culture supernatant with 0.2 volume of polyethylene glycol (PEG) solution (2.5 M NaCl, $20 \%$ (w/v) PEG 8000), and the phage pellets were redissolved in PBS (10 mM Na $\mathrm{HPO}_{4} / \mathrm{KH}_{2} \mathrm{PO}_{4}, 150 \mathrm{mM} \mathrm{NaCl}$ ). The phage suspension was passed through a $0.45 \mu \mathrm{m}$ pore-size filter (Millex GP, Millipore) before kept at $4^{\circ} \mathrm{C}$.

The number of phage particles in suspension was counted by mixing $100 \mu \mathrm{l}$ of serial diluted phage suspension and $100 \mu \mathrm{l}$ of exponential-phase $E$. coli with $4 \mathrm{ml} \mathrm{soft}$ agar $(0.7 \%)$ and pouring onto $2 \times$ YT plate before being incubated overnight at $37^{\circ} \mathrm{C}$.

Protein expression and purification

Since the amber stop codon inserted at the junction of the target gene and gene III is complete effective in E. coli HB2151, protein expression was carried out in this strain. Expression of the recombinant cellulases in E. coli HB2151 was induced by isopropyl- $\beta$-D-thiogalactopyranoside (IPTG) according to the provider's protocol with minor modifications (Amersham Bioscience). Briefly, E. coli HB2151 colony harboring the appropriate phagemid was picked to $5 \mathrm{ml} 2 \times \mathrm{YT}-\mathrm{AG}$ and cultured overnight at $30^{\circ} \mathrm{C}$. The overnight culture was inoculated into $50 \mathrm{ml}$ of $2 \times$ YT-AG followed by incubation for another hour under the same conditions. Cells were collected by centrifugation and resuspended in $50 \mathrm{ml}$ of $2 \times$ YT-AI with $1 \mathrm{mM}$ of IPTG. The culture continued at $30^{\circ} \mathrm{C}$ for $24 \mathrm{~h}$ before the supernatant containing the soluble recombinant cellulases was obtained by centrifugation. The culture supernatant was further concentrated before being loaded onto a sepharose G100 (pharmacia) column. Fractions containing respective cellulase activities toward either CMC (sigma) for endoglucanase or 4-methylumbelliferyl- $\beta$-D-cellobiose (MUC) (sigma) for exoglucanase were collected and exchanged to $20 \mathrm{mM}$ sodium acetate (NaAc) buffer, $\mathrm{pH}$ 5.8. The samples were loaded onto a DEAE sepharose FF (pharmacia) anion exchange column and the column was eluted with a linear gradient of $0-0.5 \mathrm{M} \mathrm{NaCl}$. Fractions containing $\mathrm{CBH} \mathrm{I}$ and $\mathrm{EG} \mathrm{I}$ were resolved by 
sodium dodecyl sulfate-polyacrylamide gel electrophoresis (SDS-PAGE, 10\%) (Laemmli 1970). Zymogram analysis of of EG I and CBH I were carried out according to the method described previously (Medve et al. 1998).

\section{Activity assays}

The endoglucanase activity of EG I was determined by analyzing the reducing sugars by the Smogyi method (Smogyi 1952). EG I was incubated with sodium carboxymethyl cellulose $(0.1 \% \mathrm{CMC})$ at $50^{\circ} \mathrm{C}$. One unit of EG I activity was defined as the amount of enzyme that produced $1 \mu \mathrm{mol}$ reducing sugars/min. $p$-Nitrophenyl- $\beta$-Dcellobiose ( $p$-NPC) was the substrate for assay of the enzymatic activity of CBH I (Deshpande et al. 1984). $p$-NPC (1 mg/ml in $50 \mathrm{mM} \mathrm{NaAc} \mathrm{pH} \mathrm{5.0)} \mathrm{was} \mathrm{incubated}$ with $\mathrm{CBH} \mathrm{I}$ at $50^{\circ} \mathrm{C}$. The reaction was terminated by the addition of $1 \% \mathrm{Na}_{2} \mathrm{CO}_{3}$. The released $p$-nitrophenol was measured by the absorbance at $410 \mathrm{~nm}$. One unit of CBH I activity was defined as the amount of enzyme that released of $1 \mu \mathrm{mol} p$-nitrophenol $/ \mathrm{min}$.

\section{Cellulose-binding assays}

Cellulose binding abilities of the phage-displayed EG I and CBH I were assayed by an ELISA method with filter paper (Whatman No. 1) as the immobilized substrate coated in a 96-well plastic microtiter plate (Costar). The 96-well plates were blocked with $10 \%$ (w/v) of non-fat milk in PBS for an hour. Phage solution in PBS was preincubated with the blocking buffer for $30 \mathrm{~min}$ before being transferred to the pre-coated microtitre plate and incubated for an hour. The plates were then washed sequentially three times with PBST (Tween 20, 0.05\%) and three times with PBS. The diluted horseradish peroxidase-conjugated anti-phage antibody (Amersham Bioscience) solution was added and incubated for an hour. After extensive washing, ABTS reagent containing $0.05 \% \mathrm{H}_{2} \mathrm{O}_{2}$ was added to each well. The supernatant was quantified by measuring the absorbance at $410 \mathrm{~nm}$.

\section{Results and discussion}

Phagemid construction to display cellulases

from $T$. reesei

Two recombinant phagemids, $\mathrm{pEG} \mathrm{I}$ and $\mathrm{pCBH} \mathrm{I}$, to express and display the endoglucanase EG I and cellobiohydrolyase CBH I, respectively, were constructed (Fig. 1). The amplified DNA fragments of $c b h I$ and eg $I$ encoded their corresponding mature forms of enzyme without the signal sequence and the stop condon. The recombinant phagemids were isolated from the culture supernatant of respective recombinant colonies and were verified by enzymatic digestion and DNA sequencing.

Production of EG I and CBH I in E. coli

To investigate whether $E$. coli transfected with the constructed phagemids could express the cellulases in their active forms, protein expression was carried out in E. coli HB2151 because of its inability to suppress the amber codon introduced between the target gene and gene III. Distinctive bands of CBH I and EG I were detected from the culture supernatant of $E$. coli transfected with the appropriate phagemids by SDS-PAGE after induction with IPTG as compared to the secreted proteins of transfected E. coli HB2151 without induction (Fig. 2). The apparent mobility of CBH I and EG I corresponded to molecular masses which, however, were slightly larger than the theoretically calculated molecular masses. The reason for this discrepancy might lie in the fact that the recombinant cellulases contain an in-frame-fused E-tag. Activities of the recombinant cellulases were further confirmed by active staining of the native-PAGE-resolved expressed proteins of E. coli HB2151 transfectd with recombinant phagemids (Fig. 3). Taken together, recombinant cellulases as mediated by incorporating in the phagemid vectors were successfully expressed in E. coli $\mathrm{HB} 2151$.

Phage display of EG I and CBH I

To test whether the relative cellulases displayed on the surface of phage M13 also kept their activities, recombinant phagemids were transfected into $E$. coli TG1. The phage particles were prepared and carefully purified by PEG precipitation to preclude any contaminating soluble proteins. Significant enzymatic activities for both phageexposed EG I and phage-exposed CBH I were observed for phage particles of transfected $E$. coli as demonstrated by their activities toward CMC and $p$-NPC, repsectively (Table 1). In contrast, no activities were detected for control particles where only empty phagemid vectors used to transfect $E$. coli. Interestingly, compared with phage-displayed counterparts, enzyme activities of soluble EG I or CBH I expressed by E. coli HB2151 were around 3 fold higher. Nonetheless, considering that wild-type P III would compete with P III fused to cellulases in the phage rescue process resulting in no more than $30 \%$ of the phage displaying the recombinant enzyme (Kehoe and Kay 2005; Verhaert et al. 1999), the specific activity/phage-exposed cellulase was in reasonable agreement with the measured enzymatic activity of its corresponding soluble recombinant cellulase. Overall, the results indicated that, as expected, recombinant cellulases in their active forms were 
Fig. 2 Recombinant expression and purification of $\mathrm{CBH}$ I $(\downarrow)$ (a); and EG I ( $\nabla)(\mathbf{b})$. SDS-

PAGE analysis of crude extracts of uninduced cell (lane 1), induced cell (lane 2), purified recombinant $\mathrm{CBH}$ I and $\mathrm{EG}$ I (lane 3 and 4), and low molecular weight marker with the corresponding molecular mass (lane 5)

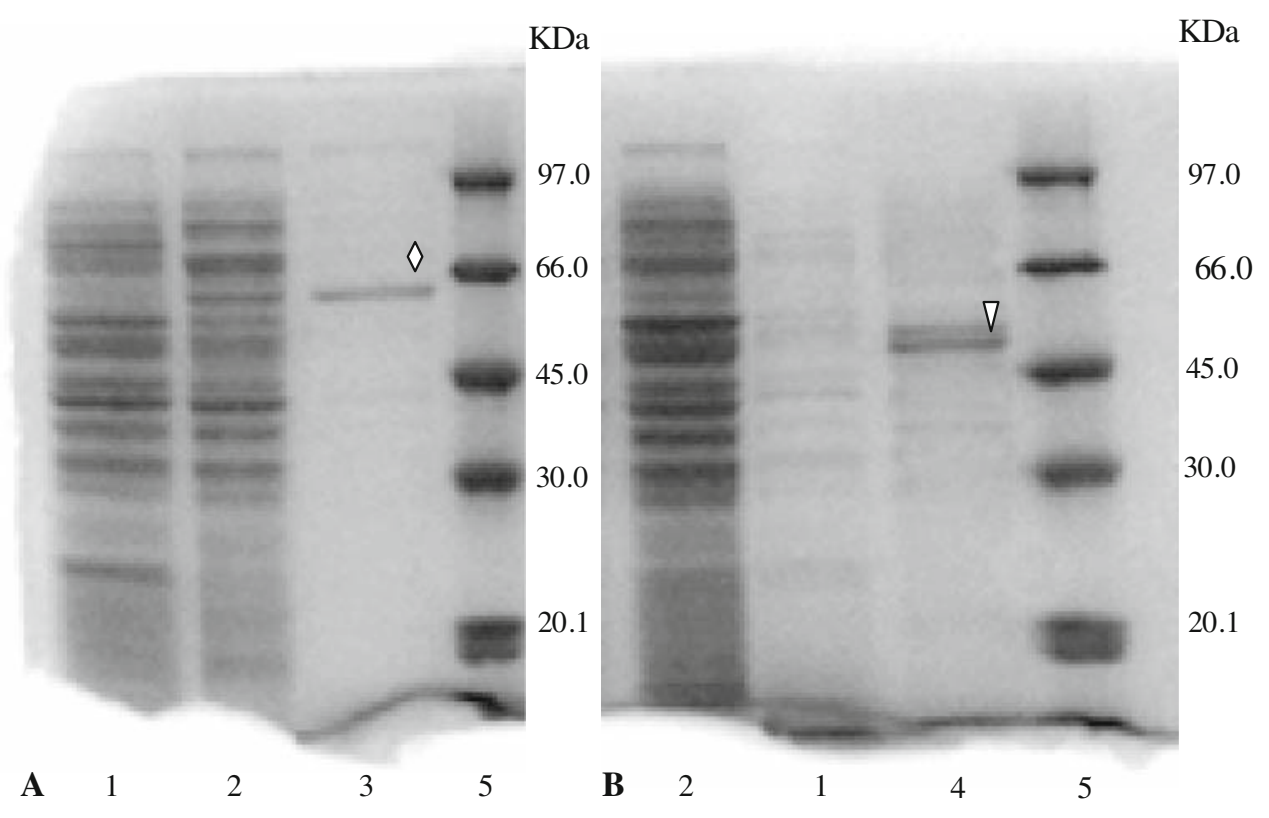

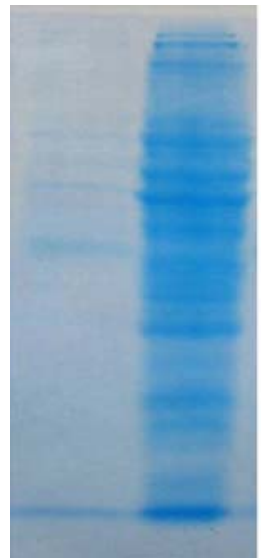

A 1

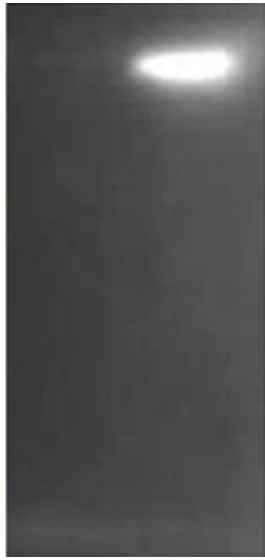

2

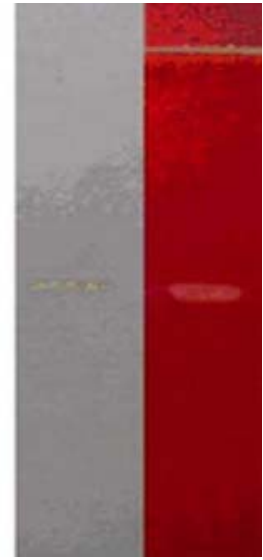

B $3 \quad 3$

Fig. 3 Native PAGE (left) and zymogram (right) analysis of recombinant $\mathrm{CBH}$ I (a) and EG I (b) Crude extracts of HB 2151 (lane 1), expressed protein of induced transfected recombinant cells (lane 2, 3) properly displayed on the phage tip through fusing to P III via its C-terminal cellulose binding domain. Potential structural constraints caused by fusing cellulases to an exogenous P III, however, did not significantly compromise the display of functional cellulases.

To further evaluate whether the phage-displayed celluases retained the ability to bind to insoluble cellulose substrate, recombinant phage particles were incubated with filter paper discs precoated in the microtiter plate and the bound phage mediated by cellulases were analyzed by ELISA as described in materials and methods. While wildtype phages, M13KO7, were easily washed away from the filter paper, recombinant phages with surface displayed $\mathrm{CBH}$ I and EG I bound tightly to cellulose filter paper (Fig. 4). This observation, together with above activity assays, demonstrated that the phage-displayed cellulases by fusing with P III protein not only kept their catalytic activity, but also retained the ability to bind insoluble

Table 1 Activity assay of phage-exposed enzyme and the corresponding soluble enzyme

\begin{tabular}{|c|c|c|c|}
\hline Enzyme type & $\begin{array}{l}\text { Activity of phage } \\
\text { suspension }\left(\times 10^{-3} \mathrm{U} / \mathrm{ml}\right)^{\mathrm{a}}\end{array}$ & $\times 10^{13} \mathrm{pfu} / \mathrm{ml}^{\mathrm{b}}$ & $\begin{array}{l}\times 10^{-18} \mathrm{U} / \text { phage } \\
\text { particle }\end{array}$ \\
\hline Phage-exposed EG I & 1.6 & 2.1 & 77 \\
\hline Phage-exposed CBH I & 0.007 & 5.0 & 0.14 \\
\hline Soluble CBH I & 48.2 & & 0.44 \\
\hline Soluble EG I & 0.272 & & 244 \\
\hline
\end{tabular}

\footnotetext{
a The catalytic activity was assayed as described in materials and methods

${ }^{b}$ Numbers of phage particles were determined by titration (plague-forming units)

c The activity/phage particle was calculated from the activity of phage solution and its numbers of phage particles. For calculation of the activity/ soluble enzyme (the corresponding soluble enzyme) molecular, the protein concentration was analyzed routinely
} 


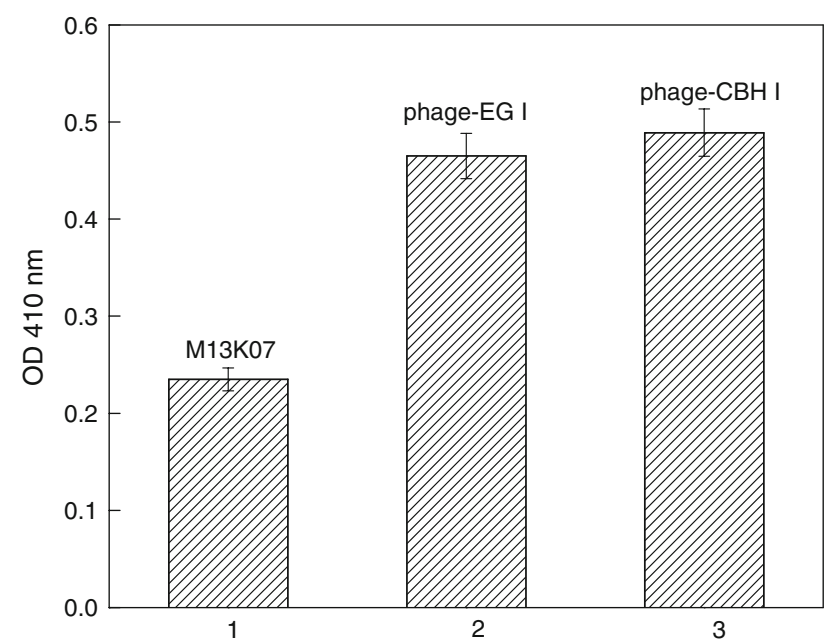

Fig. 4 The cellulose binding ability of phage-displayed cellulases. The binding abilities of wild-type M13KO7 (bar 1), phage-displayed endoglucanase I (bar 2) and phage-displayed cellobiohydrolase I (bar 3) were indirectly analyzed as determined by absorbance at OD $410 \mathrm{~nm}$ with the ELISA method

cellulose substrates, both of which are key determinants for the full biological function of cellulases.

\section{Conclusion}

Both endoglucanase I and cellobiohydrolase I (CBH I) from Trichoderma reesei were functionally expressed and displayed on the phage surface in their enzymatically active forms. The phage-bound cellulases not only retained their catalytic activities as determined by hydrolysis of the corresponding soluble substrates, but also maintained their binding abilities to insoluble cellulose substrates as confirmed by an ELISA method. Our results presented here indicated that the successful display of these key enzymes in cellulose hydrolysis would provide a technology platform for screening or selection of enzymes with improved catalytic properties produced by directed evolution considering the easy manipulation and the huge library capacity provided by phage display. Compared with systems involving cytoplasmic or secreted enzymes, screening phage-displayed enzymes could avoid the requirement of cell breakage as well as expression-normalization before the evaluation of changes in specific enzyme activities. Besides, DNA sequences encoding the desired enzyme variant could also simultaneously be retrieved and determined.

Acknowledgments This work was supported by National Science Found (No. 30370036) of China, National Basic Research Found (2003CB716000 and 2004CB719700) and Fund of Glycosylation Research Group in Shandong University.

\section{References}

Atwell S, Wells JA (1999) Selection for improved subtiligases by phage display. Proc Natl Acad Sci USA 96:9497-9502

Cherry JR, Fidantsef AL (2003) Directed evolution of industrial enzymes: an update. Curr Opin Biotechnol 14:438-443

Chirumamilla RR, Muralidhar R, Marchant R, Nigam P (2001) Improving the quality of industrially important enzymes by directed evolution. Mol Cell Biochem 224:159-168

Demain AL, Newcomb M, Wu JH (2005) Cellulase, clostridia, and ethanol. Microbiol Mol Biol Rev 69:124-154

Deshpande MV, Eriksson KE, Pettersson LG (1984) An assay for selective determination of exo-1,4,-beta-glucanases in a mixture of cellulolytic enzymes. Anal Biochem 138:481-487

Fernandez-Gacio A, Uguen M, Fastrez J (2003) Phage display as a tool for the directed evolution of enzymes. Trends Biotechnol 21:408-414

Jarvis M (2003) Chemistry: cellulose stacks up. Nature 426:611-612

Kamm B, Kamm M (2004) Principles of biorefineries. Appl Microbiol Biotechnol 64:137-145

Kehoe JW, Kay BK (2005) Filamentous phage display in the new millennium. Chem Rev 105:4056-4072

Kim YS, Jung HC, Pan JG (2000) Bacterial cell surface display of an enzyme library for selective screening of improved cellulase variants. Appl Environ Microbiol 66:788-793

Kirk O, Borchert TV, Fuglsang CC (2002) Industrial enzyme applications. Curr Opin Biotechnol 13:345-351

Laemmli UK (1970) Cleavage of structural proteins during the assembly of the head of bacteriophage T4. Nature 227:680-685

Lynd LR, Weimer PJ, van Zyl WH, Pretorius IS (2002) Microbial cellulose utilization: fundamentals and biotechnology. Microbiol Mol Biol Rev 66:506-577

Mansfield SD, Mooney C, Saddler JN (1999) Substrate and Enzyme Characteristics that Limit Cellulose Hydrolysis. Biotechnol Prog 15:804-816

McCarthy JK, Uzelac A, Davis DF, Eveleigh DE (2004) Improved catalytic efficiency and active site modification of 1,4-beta-Dglucan glucohydrolase A from Thermotoga neapolitana by directed evolution. J Biol Chem 279:11495-11502

Medve J, Lee D, Tjerneld F (1998) Ion-exchange chromatographic purification and quantitative analysis of Trichoderma reesei cellulases cellobiohydrolase I, II and endoglucanase II by fast protein chromatograph. J Chromatogr A 808:153-156

Moreira N (2005) Growing expectations: new technology could turn fuel into a bump crop. Sci News Online 168:209-224

Otten LG, Quax WJ (2005) Directed evolution: selecting today's biocatalysts. Biomol Eng 22:1-9

Ponsard I, Galleni M, Soumillion P, Fastrez J (2001) Selection of metalloenzymes by catalytic activity using phage display and catalytic elution. Chembiochem 2:253-259

Ragauskas AJ, Williams CK, Davison BH, Britovsek G, Cairney J, Eckert CA, Frederick WJ Jr, Hallett JP, Leak DJ, Liotta CL, Mielenz JR, Murphy R, Templer R, Tschaplinski T (2006) The path forward for biofuels and biomaterials. Science 311:484-489

Sheng Y, Mancino V, Birren B (1995) Transformation of Escherichia coli with large DNA molecules by electroporation. Nucleic Acids Res 23:1990-1996

Smith GP (1985) Filamentous fusion phage: novel expression vectors that display cloned antigens on the virion surface. Science 228:1315-1317

Smogyi M (1952) Notes on sugar determination. J Biol Chem 195:19-23

Verhaert RM, Beekwilder J, Olsthoorn R, van Duin J, Quax WJ (2002) Phage display selects for amylases with improved low $\mathrm{pH}$ starch-binding. J Biotechnol 96:103-118 
Verhaert RM, Van Duin J, Quax WJ (1999) Processing and functional display of the $86 \mathrm{kDa}$ heterodimeric penicillin $\mathrm{G}$ acylase on the surface of phage fd. Biochem $J$ 342: 415-422

Wittrup KD (2001) Protein engineering by cell-surface display. Curr Opin Biotechnol 12:395-399
Wong TS, Zhurina D, Schwaneberg U (2006) The diversity challenge in directed protein evolution. Comb Chem High Throughput Screen 9:271-288

Zhang YH, Himmel ME, Mielenz JR (2006) Outlook for cellulase improvement: screening and selection strategies. Biotechnol Adv 24:452-481 